\title{
Nurse Practitioner and Physician Collaboration in Long-Term Care Homes: Survey Results
}

Faith Donald, RN(EC), NP-PHC, PhD,${ }^{1}$ E. Ann Mohide, RN, MHSc, MSc,${ }^{2}$ Alba DiCenso, RN, $\mathrm{PhD},{ }^{2,3}$ Kevin Brazil, PhD, ${ }^{3}$ Michael Stephenson, MD, MSc, ${ }^{2,4}$ and Noori Akhtar-Danesh, $\mathrm{PhD}^{2,3}$

School of Nursing, Ryerson University, Toronto, Ontario, CANADA ${ }^{1}$; School of Nursing ${ }^{2}$, Departments of Clinical Epidemiology and Biostatistics ${ }^{3}$, and Family Medicine ${ }^{4}$, McMaster University, Hamilton, Ontario, CANADA

\section{Corresponding Author:}

Faith Donald

Daphne Cockwell School of Nursing, Ryerson University

350 Victoria Street

Toronto, ON M5B 2K3 Canada

Tel: (416) 979-5000 ext. 6309

Fax: (416) 979-5332

fdonald@ ryerson.ca (e-mail address may be published)

\section{Alternate Corresponding Author: \\ E. Ann Mohide \\ eamoh@mcmaster.ca}

Funding Sources: We gratefully acknowledge funding from the Ontario Ministry of Health and Long-Term Care, Nursing Secretariat.

Running Head: NP-MD Collaborative Practice

Word Count: 5616, Abstract Word Count: 149

Tables: 6

References: 35

Keywords: collaboration; nursing homes; multi-disciplinary care team; nurse practitioners; physicians 


\section{Authors:}

Faith Donald, RN(EC), NP-PHC, PhD

Associate Professor

Daphne Cockwell School of Nursing, Ryerson University

CHSRF Postdoctoral Fellow

Affiliate Faculty, CHSRF/CIHR Chair Program in Advanced Practice Nursing

School of Nursing, McMaster University

E. Ann Mohide, RN, MHSc, MSc

Associate Professor

School of Nursing, McMaster University

Alba DiCenso, RN, PhD

Professor, Nursing and Clinical Epidemiology \& Biostatistics

CHSRF/CIHR Chair in Advanced Practice Nursing

Director, Ontario Training Centre in Health Services \& Policy Research

School of Nursing, McMaster University

Kevin Brazil, $\mathrm{PhD}$

Associate Professor

Clinical Epidemiology \& Biostatistics, McMaster University

Director, St. Joseph's Health System Research Network, Hamilton, ON

Michael Stephenson, MD, MSc

Medical Director of Care, Wellington Nursing Home, Hamilton, ON

Noori Akhtar-Danesh, PhD

Associate Professor

School of Nursing, and Clinical Epidemiology \& Biostatistics, McMaster University 
NP-MD Collaborative Practice 3

\section{Acknowledgements:}

The authors wish to thank Kwadwo Bosompra, $\mathrm{PhD}$ for his assistance with the statistical components of this study and Célyne Laflamme for the French translation of the abstract. 
NP-MD Collaborative Practice 4

\begin{abstract}
This survey assessed the extent of and satisfaction with collaboration between physicians and nurse practitioners (NPs) working in Ontario long-term care homes. Questionnaires, that included the Measure of Current Collaboration and Provider Satisfaction with Current Collaboration instruments, were mailed to NPs and physicians with whom the NP most frequently worked. The 14 matched-pairs of NPs and physicians, reported similar levels of collaboration; however, physicians were significantly more satisfied with collaboration than NPs $(Z=-2.67, p=0.008)$. The majority of physicians $(85 \%)$ and NPs $(86 \%)$ indicated that collaboration was occurring and $96 \%$ of physicians and $79 \%$ of NPs were satisfied with their collaboration. About one-third of physicians reported that the NP had a negative effect on their income, but their satisfaction with collaboration did not differ from those who reported a positive effect. Overall, these physicians and NPs collaborate in delivering care and are satisfied with their collaboration.
\end{abstract}


NP-MD Collaborative Practice 5

\section{Résumé}

Dans cette étude transversale, on a mesuré l'étendue et la satisfaction de la collaboration entre les médecins et les infirmières praticiennes (IP) travaillant dans des maisons de soins de longue durée en Ontario. Des questionnaires, qui incluaient les instruments Mesure de Collaboration Courante et Satisfaction du Prestataire avec la Collaboration Courante, ont été envoyés par la poste aux IP et aux médecins avec qui les IP travaillent le plus fréquemment. La comparaison de 14 questionnaires appariés entre les IP et les médecins a démontré des niveaux de collaboration similaires. Cependant, les médecins étaient considérablement plus satisfaits avec la collaboration que les IP $(Z=-2.67, p=0.008)$. La majorité des médecins $(85 \%)$ et des IP $(86 \%)$ ont indiqués que la collaboration se produisait et $96 \%$ des médecins et $79 \%$ des IP étaient satisfaits avec la collaboration. Environ un tiers des médecins ont indiqués que les IP ont eu un effet négatif sur leurs revenus mais leur satisfaction avec la collaboration n'a pas changée par rapport à ceux qui ont rapporté un effet positif. En général, ces médecins et ces IP collaborent dans la prestation des soins et sont satisfaits de leur collaboration. 
NP-MD Collaborative Practice 6

The increasingly complex needs of elderly residents in long-term care (LTC) homes and physician shortages have been driving forces for the introduction of NPs into Ontario LTC homes and the creation of collaborative relationships with physicians (Stolee, Hillier, Esbaugh, Griffiths, \& Borrie, 2006). Historically, collaboration between physicians and nurse practitioners (NPs) has been reported by some as satisfying, by others as challenging, and by some as mixed experiences (Caprio, 2006; Keith \& Askin, 2008; Ryan, 1999; Stevenson, Kamholz, \& Siegler, 1994). Physician territoriality and NP role confusion are two important obstacles to effective collaboration (Caprio, 2006; Neale, 1999).

\section{Review of the Literature}

A Cochrane review examining physician-nurse collaboration in healthcare settings between 1967 and 2000 revealed that little empirical research exists on this topic and that relevant literature is predominantly editorial or speculative in nature (Zwarenstein \& Reeves, 2000). The review identified theories and hypotheses that sought to describe collaboration.

A 2007 study of the NP role in pain management in LTC homes found that poor collaboration between the physicians and NPs was a barrier to effective pain management (Kaasalainen, DiCenso, Donald, \& Staples, 2007). Few research studies specific to collaboration in LTC homes are reported (Abdallah, Fawcett, Kane, Dick, \& Chen, 2005; Rosenfeld, Kobayashi, Barber, \& Mezey, 2004; Stolee, Hillier, \& æstima research, 2002) and only one includes both NPs and physicians (Stolee et al., 2002). Abdallah et al. (2005) found that NPs' collaborative practice activities included collaborating with the physician for diagnosing and/or managing acute and chronic issues, and calling the physician with patient status changes; physicians were not 
sampled in this study. In a mailed survey of physician members of the American Medical Directors Association, Rosenfeld and colleagues (2004) found that the majority reported adequate collaboration between the NP and physician and that $90 \%$ of the physician respondents were satisfied with NP practice.

When NPs were introduced into selected Ontario LTC homes in 2000, there was an expectation that NPs and physicians would collaborate to meet residents' primary care needs (Stolee et al., 2006). In a qualitative program evaluation, Stolee and Hillier (2002) examined the roles, perceived outcomes, and barriers to the establishment of this new NP role. Data collection included an NP focus group and individual interviews with physicians, NPs, administrators, directors of care, and registered nurses but matched-pair physician and NP comparison was not done. Stolee and Hillier found that the NPs' heavy workloads compromised their ability to establish collaborative relationships with physicians. Concern about physicians' remuneration for the time required to collaborate with the NPs was raised by some participants as a potential financial disincentive for working with NPs in LTC homes. However, findings indicated that the collaborative nature of NP and physician work in LTC homes resulted in more efficient use of physician time.

Way, Jones, and Busing (2000) define collaborative practice as "an inter-professional process for communication and decision making that enables the separate and shared knowledge and skills of care providers to synergistically influence the client/patient care provided" (p. 3). Their definition was adopted for this study, as it incorporates the major components of collaboration 
found in the literature and recognizes that collaboration is a process, rather than limiting the definition to interactions between different types of healthcare providers.

The objectives of this study were to assess the extent to which physicians and NPs, working in Ontario LTC homes, collaborate and their satisfaction with that collaboration.

\section{Methods}

In this cross-sectional study, a questionnaire was mailed to NPs and physicians who worked together in LTC homes. Ethics Review Board approval was received from Ryerson University and McMaster University. Funding for the study was provided by the Ontario Ministry of Health and Long-Term Care (MoHLTC), Nursing Secretariat.

\section{Setting and Sample}

The LTC homes were residential for-profit nursing homes and not-for-profit homes-for-the-aged in Ontario, hereafter referred to as homes. Homes were excluded if their focus was on retirement, rehabilitation, complex continuing care, paediatrics, or acute care. For the purposes of this study, an NP was defined as a registered nurse with additional university education as a primary health care or family NP and an extended class license, with the independent authority to perform advanced nursing skills and activities, and to diagnose, order and interpret diagnostic tests, and prescribe medications (College of Nurses of Ontario, 2006). Primary health care NPs who held licensure in the College of Nurses of Ontario extended class, were currently working in LTC homes, and were directly funded by the MoHLTC were eligible for study inclusion. NPs on a leave-of-absence were excluded. Licensed physicians who focused on family practice and 
NP-MD Collaborative Practice 9

worked in homes with the NPs were eligible for inclusion in the study. Ability to read and write English was an inclusion criterion for both groups.

\section{Questionnaire Development}

The NP and physician questionnaires were developed by the research team and included selected questions from a previous study (DiCenso, Paech, \& IBM Corporation, 2003) and the adaptation of two instruments, the Measure of Current Collaboration (MCC) and the Provider Satisfaction with Current Collaboration (PSCC) (Way, Jones, \& Baskerville, 2001). While psychometric testing of these instruments had not been done, their use in previous studies confirmed that the instrument items were understandable, relevant, and demonstrated face validity for NPs and physicians across Ontario (DiCenso et al., 2003; Way et al., 2001).

The MCC contains nine items about the nature and extent of current collaboration between the NP and physician and the PSCC has 11 items designed to measure provider satisfaction with current physician-NP collaboration (Way et al., 2001). The original Jones and Way collaboration instruments had 7-point Likert scale response options, ranging from 1 [strongly agree (MCC)/very satisfied (PSCC)] to 7 [strongly disagree (MCC)/very dissatisfied (PSCC)], with 4 representing neutral; mean instrument scores were calculated by summing the score for each item and then dividing the score by the number of items. For this study, the Likert-scale response options were reverse scored to be consistent with other Likert scales in the questionnaire (McColl et al., 2001). In order to encourage each respondent to declare an opinion about the extent of their collaboration and their level of satisfaction with that collaboration (Converse \& 
Presser, 1986) and to avoid interpretation challenges, and central tendency bias, the neutral option was omitted. Consequently, each item was scored using a 6-point Likert scale ranging from 1 (strongly disagree/strongly dissatisfied), 2 (disagree/dissatisfied), 3 (slightly disagree/slightly dissatisfied), 4 (slightly agree/slightly satisfied), 5 (agree/satisfied), and 6 (strongly agree/strongly satisfied). The term resident was substituted for patient to reflect common terminology in LTC.

There were two parts to the physician and NP questionnaires; Part A included items designed to learn more about the participants: 1) demographics (e.g., age, sex, education, length of practice); 2) previous experience with NP-physician collaboration; and, 3) for the physicians, method of payment for services provided in the homes and the perceived impact of the NP on their income. Some have speculated that previous experience with physician-nurse collaboration may help to improve subsequent collaboration (Henneman, Lee, \& Cohen, 1995; Hojat et al., 2001). To examine whether previous experience with physician-NP collaboration related to the current collaborative relationship, respondents were asked if they had previous experience with NPphysician collaboration. If so, they were asked to identify the setting where the previous collaboration occurred and their satisfaction with the previous collaborative relationship.

Part B of the questionnaires included questions and statements intended to: 1) learn more about the homes in which they worked (e.g., number of homes and the size and location of each); 2) describe the physician-NP collaborative practice structure and processes (e.g., time spent collaborating, communication methods); and, 3) quantify the extent of (MCC) and satisfaction 
NP-MD Collaborative Practice 11

with (PSCC) current NP-physician collaboration. Four questions about satisfaction with collaboration were added to examine aspects not covered in the PSCC. These questions addressed satisfaction with the availability of the collaborating partner, amount of time spent consulting with one another, satisfaction with the appropriateness of consultations, and the quality of care provided by the collaborating partner (DiCenso et al., 2003). These four additional questions were also scored on a 6-point Likert scale ranging from 1 to 6 (strongly dissatisfied to strongly satisfied). Physicians were asked whether or not the NP role affected their income, and if so, whether in a positive or negative way. The NPs were asked to identify all methods of communication (e.g., telephone, health record) and reasons for interaction with the physicians (e.g., regularly scheduled meetings, as needed for resident situations).

The questionnaires were pilot tested with three NPs and three physicians who worked in Ontario homes, but who did not meet inclusion criteria because they were not directly funded by the MoHLTC. The physician and NP respondents reported that the questionnaire items were clear, comprehensive, and applicable to NP-physician collaboration in LTC homes. Psychometric testing of the two instruments was not completed for this study due to the small population of NPs $(N=18)$ directly funded by the MoHLTC.

\section{Data Collection Strategy}

An e-mail was sent to all 18 NPs who were funded by the MoHLTC to work in Ontario longterm care homes. The e-mail introduced the study and the inclusion and exclusion criteria. Based on their replies, three NPs were excluded as one was not registered in the extended class and two 
NP-MD Collaborative Practice 12

were on a leave-of-absence. The NPs were asked to provide the name of the one family practice physician with whom they worked most frequently at each home, so that a questionnaire could be sent to the collaborating physician. The NPs identified 33 physicians with whom they frequently worked. This number of physicians reflects the fact that most of the NPs worked in more than one home, typically with different MDs at each home. Of the 15 eligible NPs, seven NPs each identified one physician with whom they frequently worked, four NPs each identified two physicians, three NPs each identified three physicians, and one NP identified nine physicians with whom she most frequently worked. Three NPs identified that they worked equally often with two MDs per home. None of the identified physicians worked with more than one NP.

Fifteen NPs were mailed one copy of Part A of the questionnaire (demographic data) and sufficient copies of Part B so that each NP could complete one Part B for each physician identified by the NP. Parts A and B of the physician questionnaire were mailed to the 33 physicians. The corresponding collaborative partner's name was written on the questionnaire to ensure that the data could be matched by pairs.

Edwards et al.'s (2002) recommendations to increase questionnaire response rates were used: the initial mailed questionnaire included a personalized cover letter, a $\$ 5.00$ gift certificate to a nation-wide coffee shop, and a self-addressed stamped envelope. Two weeks later, a second questionnaire was mailed to nonrespondents. The third questionnaire mailing to nonrespondents, sent three weeks after the second mailing, included a brief, hand-written note soliciting responses and a second coffee shop gift certificate. Three weeks later, a fourth mailing was sent with a 
NP-MD Collaborative Practice 13

brief cover letter signed by a research team member (M.S.) who is a Medical Director in a home and who did not work with the nonrespondents. Data were collected between March and June 2007.

\section{Outcome Measures}

The two main outcomes were extent of collaboration and satisfaction with collaboration for NPs and physicians working in LTC homes. Secondary outcomes included the physicians' perceptions of the impact of the NP role on their income, the relationship between current perceptions of collaboration for those who did and did not have previous experience with physician-NP collaboration, and the NPs' reported communication methods and reasons for interactions with the physicians.

\section{Data Analysis}

Data were analyzed using descriptive statistics and nonparametric tests with SPSS version 14.0 for Windows (SPSS Inc., Chicago, IL). Nonparametric statistical testing was used because the physician instrument scores were not normally distributed. The Wilcoxon matched-pairs signedrank test was used to measure the differences between the matched-pairs of NPs and physicians for the MCC and PSCC instruments (Howell, 2002). The four additional satisfaction with collaboration items were analyzed separately from the PSCC instrument using the Wilcoxon matched-pairs signed-rank test. The Mann-Whitney U test was used to test the difference between the instrument scores for those individuals with and without previous NP-physician 
NP-MD Collaborative Practice 14

collaborative experience and to determine if an impact on physician income affected instrument scores. Probability levels were set at $p<0.05$.

\section{Results}

\section{NP Demographics}

Of the 15 NPs, 14 (93\%) returned 14 completed Part A and 32 completed Part B questionnaires. All 14 NPs were female, employed full-time, and baccalaureate prepared. Three respondents also had a master's degree. Almost all (93\%) had obtained their NP education through the Ontario Primary Health Care Nurse Practitioner Program offered collaboratively at 10 universities and had graduated between one and 10 years ago, with the median graduating 4 years ago. The NPs were middle-aged with many years of previous RN experience and had been NPs for approximately 4 years, the majority of which was spent in a LTC home (Table 1).

Insert Table 1 here

Ten NPs worked in more than one home (Table 2), typically with a different physician in each home. Approximately $70 \%$ of the NPs worked in one to two homes. As the number of homes in which the NP worked increased, the number of hours per month spent in each home and the time spent collaborating with the identified physician decreased.

Insert Table 2 here 


\section{Physician Demographics}

Of the 33 physicians, three did not return the questionnaire and three returned incomplete questionnaires. Of the 27 physicians who returned complete questionnaires, $23(85 \%)$ were male. The physicians completed medical school between 1954 and 2000, with a median graduation year of 1974. Over half (52\%) of the physician respondents were Medical Directors. Most physicians were middle-aged with substantial experience working in LTC homes. On average, the physicians collaborated with the NP approximately two hours per month and they had worked together for a median of 2 years (Table 3). Most physicians divided their time between office practice and other settings, such as the emergency department and other homes, and 10 were semi-retired. One physician was employed full-time at one home.

Insert Table 3 here

\section{LTC Home Settings}

The 14 NPs worked in a total of 36 LTC homes. For-profit nursing homes accounted for 29 $(81 \%)$ and $7(19 \%)$ were not-for-profit homes for the aged. There was a median 140 residents per home $(\min =38, \max =378)$, and $22(61 \%)$ were located in urban and $14(39 \%)$ in rural settings.

\section{Extent of and Satisfaction with Collaboration}

Overall, the mean scores for the NPs $(n=14)$ and physicians $(n=27)$ were in the moderately positive range for both the MCC and PSCC (Table 4). However, the physicians reported a greater extent of and higher satisfaction with collaboration than did the NPs. 
Insert Table 4 here

On the six-point Likert scales, an instrument mid-point mean score of $\geq 3.5$ was considered a positive response. Using the mean 3.5 cut-point, the majority of NPs (86\%) and physicians (85\%) indicated on the MCC that collaboration was occurring, and $79 \%$ of NPs and $96 \%$ of physicians indicated satisfaction with collaboration on the PSCC (Table 5). Of the four physicians who reported on the MCC that collaboration was occurring below the 3.5 cut-point, only one indicated dissatisfaction with this on the PSCC.

Insert Table 5 here

For those NPs who worked with more than one physician, their ability to assign a different score to the MCC and PSCC for each physician was examined. The MCC and PSCC instrument score differences for each NP who scored two physicians varied from 0.89 to 3.33 and 0.73 to 2.82 respectively, and for those who identified three or more physicians, the score differences were from 1.00 to 2.22 and 1.46 to 1.73 respectively. The MCC and PSCC instrument score differences for the physicians who reported on NPs who worked in two homes varied from 0.00 to 3.12 and 0.00 to 1.00 respectively, and for those in which the NP worked in three or more homes, the score difference was 0.67 to 3.44 and 0.73 to 4.0 respectively. 
Prior to analyzing scores for matched-pairs of NPs and physicians, an overall mean score for each of the ten NPs who completed an MCC for more than one physician was calculated by averaging the mean scores for each physician. This process was repeated for the PSCC and the four additional satisfaction questions. Similarly, the corresponding physicians' scores were averaged to obtain an overall mean score for the NP. For example, in a situation where an NP identified two physicians and completed two questionnaires, an overall mean MCC instrument score was calculated by summing the two individual mean MCC instrument scores and then dividing by two. Similarly, the overall mean MCC instrument score for the NP was calculated by averaging those two physicians' individual mean MCC instrument scores. This process resulted in14 NP-physician matched-pairs.

Using the Wilcoxon matched-pairs signed-rank test, there was no statistically significant difference between physicians' and NPs' overall mean scores on extent of collaboration on the MCC instrument $(Z=-1.748, p=0.081)$. Based on the PSCC instrument results, physicians were significantly more satisfied with collaboration than the NPs $(Z=-2.67, p=0.008)$.

Of the four additional items related to satisfaction with availability, time spent consulting, appropriateness of consultations, and quality of care, physicians reported higher levels of satisfaction than NPs for all four items. The difference was statistically significant for only one item, satisfaction with appropriateness of consultations initiated by the physician/NP $(\mathrm{Z}=-2.4, p$ $=0.018$ ). 


\section{Impact of Collaboration on Physician Income}

Twenty-six (96\%) of the 27 physicians were remunerated through fee-for-service. For the 13 physicians who indicated that the NP affected their income, 8 physicians identified that the NP had a negative effect and 5 reported a positive effect on income. There were no statistically significant differences in mean instrument scores between those who reported a negative effect and those who reported a positive effect on income for the MCC $(Z=-0.540, p=0.589)$ or the $\operatorname{PSCC}(Z=-0.541, p=0.589)$.

\section{Relationship Between Previous and Current Collaboration}

Approximately half of the physicians and the NPs reported previous physician-NP collaboration. Both the physicians and NPs rated their satisfaction with previous collaboration in the moderately satisfied range $(\bar{x}=4.8 \pm 1.1 ; 4.6 \pm 1.6$ respectively) in settings such as acute care, hospital outpatient clinics, community health centers, and family health networks. None of the respondents reported previous experience with NP-physician collaboration in LTC homes.

The NPs and physicians without previous collaboration experience scored slightly higher on the MCC and PSCC instruments than did those with previous experience (Table 6). There were no statistically significant differences in the instrument scores of physicians or NPs who did or did not have previous experience with NP-physician collaboration. 
NP-MD Collaborative Practice 19

\section{Communication Methods and Reasons for Interactions}

The NPs identified methods of communication between the NPs and physicians. Communication methods varied between NPs; but, also for the same NP depending on the physician with whom she was working. Telephone discussion with the physicians was the most common form of communication, as identified by $97 \%$ of the NPs, followed by written messages (59\%), messages via staff (56\%), review of medical records (56\%), and face-to-face contact with the physician (16\%). E-mail or fax communication methods were reported by $9 \%$ of the NPs. Communication on an "as needed" basis was reported by $75 \%$ of the NPs and $22 \%$ identified regular NPphysician meetings. Participation in quarterly drug reviews or scheduled rounds were reported by $9 \%$ of the NPs.

\section{Discussion}

The physicians reported a statistically significant greater satisfaction with collaboration than did the NPs; however, both physician and NP scores were in the moderately positive range. In general, scores for physicians and NPs support Stolee and Hillier's (2002) previous qualitative findings that NPs working in Ontario LTC homes have established positive collaborative relationships with physicians. As well, these results lend support to Rosenfeld and colleagues' (2004) findings that medical directors of LTC homes reported adequate collaboration between the physician and NP. However, this study also found that some physicians and NPs did not perceive that collaboration was occurring at a level that they would have expected or were not satisfied with the collaborative relationship. While the overall scores were moderately positive, there is room for improvement in both the extent of and satisfaction with physician-NP collaboration. Poor collaboration has potentially serious implications for safety and continuity of 
NP-MD Collaborative Practice 20

care, as well as communication with residents, their family members, and LTC staff. The NP and MD may not be communicating important information to one another that could negatively influence the quality of care provided (Truscott, 2007). From a policy perspective, the MoHLTC is encouraged to require annual evaluations of how the NP and physician collaboration is going, what is going well, what needs to be improved, and what strategies have been put in place to address identified concerns and to strengthen the collaborative relationship.

The overall higher MCC and PSCC scores for physicians may reflect differences in the way physicians define or perceive collaboration compared with the NPs or the power differential between the two professions (Caprio, 2006). Differences in education of physicians and NPs may affect personal definitions of and expectations for collaboration (Fagin, 1992; Knaus, Draper, Wagner, \& Zimmerman, 1986; Larson, 1999; Scott \& Thurston, 2004; Siegler \& Whitney, 1994; Yurkow, 1999). The physicians in this study graduated from medical school on average 30 years ago when there was likely little or no education about collaboration. In the past, physicians were traditionally taught to work independently in a hierarchical system, referring to specialists rather than collaborating on a plan of care with other professionals (Ryan, 1999; Scott \& Thurston, 2004). In contrast, the NPs received their education within the last eight years and the curriculum included content about collaboration. The NPs' more recent education and the emphasis on collaboration in their education programs may help to explain the NPs' slightly lower scores on both collaboration instruments, as their expectations for collaboration likely differed from those of the physicians. 
NP-MD Collaborative Practice 21

Another explanation for the lower NP scores on the MCC and PSCC may relate to the limited NP scope of practice in Ontario. For instance, an Ontario NP can order a number of antibiotics from a legislated medication list, but if a resident develops pneumonia and the first-line antibiotic is not on the approved list, the NP must contact the physician to request the drug order. Contacting the physician can take a considerable amount of time, delaying resident care, prolonging and possibly exacerbating the disease process, and placing an additional burden on the busy physician and NP. A negative impact on satisfaction with collaboration may occur when NPs must contact and rely on physicians to order tests and medications and make diagnoses that are within the realm of the NPs' knowledge and skill, but are not within their legislated scope of practice. The variability in the NPs' instrument scores, for those who worked with more than one physician, indicated that the NPs were able to discriminate between collaborative relationships with physicians. It is not known if the time spent contacting individual physicians impacted on the MCC and PSCC scores. However, the time spent by the NP contacting physicians for orders that are within the knowledge and skill of the NP results in time being taken away from caring for residents. Medical directives that delineate courses of action based on specific criteria are an interim measure, pending changes in legislation, that can reduce the time spent contacting the collaborative partner.

Role overlap between physicians and NPs may facilitate timely access to primary care within the home given the increased availability of a qualified care provider. However, the role overlap can also lead to role confusion and "turf protection" which can impact on quality collaboration (Neale, 1999). In a literature review regarding NP and physician assistant collaboration with 
NP-MD Collaborative Practice 22

physicians in LTC, Caprio (2006) concluded that physicians fear a loss of professional identity and relevance in LTC practice. These two fears, compounded by role overlap, have created role confusion. He calls for clear role definitions for physicians and NPs to strengthen collaborative practice and enhance clinical outcomes. A written agreement, such as a collaboration contract may open dialogue between the NP and physician to discuss their roles (Truscott, 2007) and regular review is important to further clarify the roles and collaborative agreement. Clinical practice guidelines that are mutually agreed upon can further clarify the roles and decision making regarding resident care. Administrators need to work closely with the NPs and physicians to clearly define their respective roles and areas of overlap at the time the NP role is planned and at regular intervals after the role is established. Regular meetings between the NP and physician will provide a forum to discuss the quality of the collaborative relationship and strategies to strengthen the collaboration.

Some Ontario physicians have expressed concern that working with an NP might negatively impact their income (DiCenso et al., 2003; Stolee et al., 2002). Although the current study had a small number of participants, this is the first study that revealed differing views as to whether the effect was negative or positive. For those reporting a positive impact on income, the effect might relate to an increase in billing time outside the LTC homes. There were no differences in MCC or PSCC scores between physicians reporting a positive or negative effect on income, suggesting that changes in physicians' income did not influence the extent of or satisfaction with collaboration with NPs. 
NP-MD Collaborative Practice 23

Hojat et al. (2001) and Henneman, Lee, and Cohen (1995) suggested that prior experience with collaboration would facilitate future collaborative processes, but an association between previous and current collaboration was not found in this study. Previous collaboration occurred in settings other than LTC homes, such as acute care and community health centers. The previous collaboration was in settings where NPs and physicians worked together in close physical proximity, which is not the case in LTC homes. It may be that previous experience in a different type of setting does not provide an accurate comparator or guide for the current relationship. Finally, the use of a single question to measure satisfaction with previous collaboration may not have fully captured this issue.

Communication between physicians and NPs was typically via telephone on an "as needed" basis, rather than working face-to-face or during regularly scheduled meetings. There is a recognized need in the literature for regular communication to strengthen collaboration (Flaherty, 2000). Few of the NPs reported collaboration during rounds or quarterly reviews, when the goals and plans for resident care often are discussed. The reasons for NPs not collaborating during rounds and quarterly reviews were not specified. It may be that NPs did not attend these review meetings because they were not available at the time the meetings were scheduled or because they did not feel welcome to attend. While 'ad hoc' telephone communication may be satisfactory to address specific, and possibly urgent, issues as they arise, collaboration during rounds or quarterly reviews would allow the NP, physician, and healthcare team to fully discuss a resident's health status and develop a coordinated plan of care in which everyone's role is clear. Given that lack of clarity of the NP role has been a barrier to NP integration in various 
NP-MD Collaborative Practice 24

settings (DiCenso et al., 2003), these meetings would provide regular opportunities to clarify the NP's role and to articulate the NP's role in relationship to others' roles.

Stevenson, Kamholz, and Siegler (1994) postulated that communication barriers might be amplified in LTC homes when a physician is seldom on site. Most of the study physicians reported spending relatively little time on site in the LTC home, with half averaging four hours per week. In the case of NPs who work in multiple homes, their time on-site is also limited. Yet, even with this limited time to collaborate, the majority of physicians and NPs agreed that there was an adequate extent of and moderate satisfaction with collaboration. It is interesting to note that two of the three physicians who identified that collaboration was happening to a small extent were nonetheless satisfied with the collaboration. Possibly, these physicians viewed the NP as a physician extender (Caprio, 2006), an extra pair of eyes and ears thus satisfying the physicians' concerns about medical care for residents, rather than specifically being satisfied with collaboration about resident needs. It may be that increased face-to-face, planned communication to discuss resident and family needs and plans of care, as well as existing and future programs in the LTC home, and other collaborative practice decisions is needed to further strengthen these physician-NP collaborative relationships. However, the extent to which face-to-face communication is required to successfully establish, and then, maintain a strong physician-NP collaborative relationship is not known. This is an important area requiring further research.

While the NP caseload was not specifically addressed in this survey, the number of residents per home was high for those who work in multiple homes. Experts in the United States recommend 
12 to $18 \mathrm{NP}$ visits to LTC residents per day in addition to other activities such as committee work and team meetings. This recommended caseload is dependent on the experience level of the NP, resident acuity, and LTC home characteristics (Mezey et al., 2005). Policy makers are encouraged to consider these factors when planning for future NP positions in LTC.

The older cohort of physicians in this study reflects a dilemma now facing health human resource planners. According to the 2007 National Physician Survey, approximately 2100 physicians work in Ontario LTC homes and $28 \%$ of them are 55 years or older (College of Family Physicians of Canada, 2007). While older physicians may more readily identify with the aging issues of LTC residents, they may not be available to respond to emergent needs or willing to collaborate with NPs and members of the healthcare team. The existing shortage of physicians who work in LTC homes may be exacerbated as this older cohort of physicians retires. To better prepare young physicians to work in LTC, an increased curricular content about the aging process is needed in medical education programs. The teaching nursing home (Mezey, Mitty, \& Burger, 2008) is a concept that may attract medical students as they begin to formulate their career plans. If teaching nursing homes can facilitate effective collaborative relationships between physicians and NPs, the support provided by NPs to physicians might help to attract and retain physicians in LTC.

\section{Study Strengths and Limitations}

A search of the literature did not reveal any other studies that compared the perceptions of physician-NP partners with respect to the extent of and satisfaction with their collaboration or a 
NP-MD Collaborative Practice 26

matched-pair analysis. While the study may be limited by its small sample size, it has included the entire population of eligible NPs and physicians in Ontario and the response rates of both groups were very high.

This study focused on NPs and the physicians with whom the NPs most frequently collaborated in each home. Because the NP role in LTC homes typically requires collaboration with a number of physicians within each home, it would have been ideal to measure the extent of and satisfaction with collaboration between the NP and each physician with whom he or she worked. However, this was not possible because of time and budget limitations, as well as the respondent burden for the NP to complete a questionnaire for every physician.

Social desirability and self-reporting biases may have over-estimated the extent of and satisfaction with collaboration. The small number of NPs and physicians in one province limits the generalizability of the findings. Replication of this study is recommended with a larger sample size that incorporates psychometric testing of the MCC and PSCC.

\section{Conclusions}

Both physicians and NPs reported that collaboration was occurring at a moderate level and they were relatively satisfied with it. Territorialism and role confusion are recognized barriers to collaboration and require further study to determine if these are barriers to collaboration in Ontario. Ineffective collaboration is an important barrier to quality resident care (Truscott, 2007). 
Research addressing factors that support or impede collaboration in LTC homes is needed so that plans to strengthen collaboration can be developed.

To facilitate successful collaborative relationships, NP and physician partners who collaborate effectively could act as mentors for physicians and NPs for whom collaboration in LTC homes is new. As well, physician and NP attendance at interprofessional education sessions provides the opportunity for the pair to collaborate in the application of their new learning to specific resident needs.

Interprofessional collaboration has become a necessity in the current healthcare delivery system (Baggs et al., 1997). Collaborative teams of NPs and physicians in LTC homes have demonstrated reductions in hospitalizations and hospital cost savings (Kane, Keckhafer, Flood, Bershadsky, \& Siadaty, 2003), enhanced resident health knowledge, better working relationships between nurses and physicians, and improved resident access to care (Bouchard, Holdway, Corbeil, Tasse, \& Joanisse, 2004). It is important to understand the process by which individuals from two different healthcare professions collaborate in order to begin to understand how multiple professions collaborate. This study is a building block in an area where little research has been conducted to examine NP-physician collaboration in LTC homes. While this study suggests that collaboration is occurring between NPs and physicians in Ontario's LTC homes and they are moderately satisfied with their collaboration, further research is needed to understand how NPs and physicians collaborate in their daily practice in LTC homes, to identify 
NP-MD Collaborative Practice 28

the major facilitators and barriers to collaboration, to design and to evaluate interventions to improve collaboration, and to identify resident-important outcomes of collaboration. 


\section{References}

Abdallah, L., Fawcett, J., Kane, R. L., Dick, K., \& Chen, J. (2005). Development and psychometric testing of the EverCare Nurse Practitioner Role and Activity Scale (ENPRAS). Journal of the American Academy of Nurse Practitioners, 17(1), 21-26.

Baggs, J. G., Schmitt, M. H., Mushlin, A. I., Eldredge, D. H., Oakes, D., \& Hutson, A. D. (1997). Nurse-physician collaboration and satisfaction with the decision-making process in three critical care units. American Journal of Critical Care, 6(5), 393-399.

Bouchard, M., Holdway, K., Corbeil, S., Tasse, H., \& Joanisse, J. (2004). Evaluating the nurse practitioner role in LTC: Staff perceptions of the nurse practitioner's role in a long-term care setting. Canadian Nursing Home, 15(2), 7-12.

Caprio, T. V. (2006). Physician practice in the nursing home: Collaboration with nurse practitioners and physician assistants. Annals of Long-Term Care, 14(3), 17-24.

College of Family Physicians of Canada (2007). 2007 National physician surveys. Retrieved August 13, 2008, from College of Family Physicians of Canada http://www.nationalphysiciansurvey.ca/nps/2007_Survey/2007results-e.asp

College of Nurses of Ontario (2006). Extended class: Present and future. Retrieved March 9, 2008, from College of Nurses of Ontario http://www.cno.org/for/rnec/index.htm\#ov

Converse, J. M., \& Presser, S. (1986). Survey questions: Handcrafting the standardized questionnaire. Beverly Hills, CA: Sage.

DiCenso, A., Paech, G., \& IBM Corporation (2003). Report on the integration of primary health care nurse practitioners into the province of Ontario: Final report June 30, 2003. Retrieved March 9, 2008, from Ministry of Health and Long-Term Care 
NP-MD Collaborative Practice 30

http://www.health.gov.on.ca/english/public/pub/ministry_reports/nurseprac03/np_report.

pdf

Edwards, P., Roberts, I., Clarke, M., DiGuiseppi, C., Pratap, S., Wentz, R., et al. (2002).

Increasing response rates to postal questionnaires: Systematic review. BMJ, 324, 11831191.

Fagin, C. M. (1992). Collaboration between nurses and physicians: No longer a choice. Academic Medicine, 67(5), 295-303.

Flaherty, E. (2000). The nurse practitioner: Emerging issues and considerations. Ann Long Term Care, 8(7), 48-50.

Henneman, E. A., Lee, J. L., \& Cohen, J. I. (1995). Collaboration: A concept analysis. Journal of Advanced Nursing, 21(1), 103-109.

Hojat, M., Nasca, T. J., Cohen, M. J. M., Fields, S. K., Rattner, S. L., Griffiths, M., et al. (2001). Attitudes toward physician-nurse collaboration: A cross-cultural study of male and female physicians and nurses in the United States and Mexico. Nursing Research, 50, $123-128$.

Howell, D. C. (2002). Statistical methods for psychology (5th ed.). Pacific Grove, CA: Duxbury.

Kaasalainen, S., DiCenso, A., Donald, F. C., \& Staples, E. (2007). Optimizing the role of the nurse practitioner around pain management in long-term care. Canadian Journal of Nursing Research, 39(2), 14-31.

Kane, R. L., Keckhafer, G., Flood, S., Bershadsky, B., \& Siadaty, S. (2003). The effect of Evercare on hospital use. Journal of the American Geriatrics Society, 51(10), 1427-1434. 
NP-MD Collaborative Practice 31

Keith, K. M., \& Askin, D. F. (2008). Effective collaboration: The key to better healthcare. Nursing Leadership, 21(2), 51-61.

Knaus, W. A., Draper, E. A., Wagner, D. P., \& Zimmerman, J. E. (1986). An evaluation of outcomes from intensive care in major medical centers. Annals of Internal Medicine, 104, 410-418.

Larson, E. (1999). The impact of physician-nurse interaction on patient care. Holistic Nursing Practice, 13(2), 38-46.

McColl, E., Jacoby, A., Thomas, L., Soutter, J., Bamford, C., Steen, N., et al. (2001). Design and use of questionnaires: A review of best practice applicable to surveys of health service staff and patients. Executive summary. Health Technology Assessment, 5(31), iii-v.

Mezey, M., Burger, S. G., Bloom, H. G., Bonner, A., Bourbonniere, M., Bowers, B., et al. (2005). Experts recommend strategies for strengthening the use of advanced practice nurses in nursing homes. Journal of the American Geriatrics Society, 53(10), 1790-1797.

Mezey, M. D., Mitty, E. L., \& Burger, S. G. (2008). Rethinking teaching nursing homes:

Potential for improving long-term care. Gerontologist, 48(1), 8-15.

Neale, J. (1999). Nurse practitioners and physicians: A collaborative practice. Clinical Nurse Specialist, 13(5), 252-258.

Rosenfeld, P., Kobayashi, M., Barber, P., \& Mezey, M. (2004). Utilization of nurse practitioners in long-term care: Findings and implications of a national survey. Journal of the American Medical Directors Association, 5(1), 9-15.

Ryan, J. W. (1999). Collaboration of the nurse practitioner and physician in long-term care. Lippincott's Primary Care Practice, 3(2), 127-134. 
NP-MD Collaborative Practice 32

Scott, C. M., \& Thurston, W. E. (2004). The influence of social context on partnerships in Canadian health systems. Gender, Work, and Organization, 11(5), 481-505.

Siegler, E. L., \& Whitney, F. W. (1994). Social and economic barriers to collaborative practice. In E. L. Siegler \& F. W. Whitney (Eds.), Nurse-physician collaboration: Care of adults and the elderly (pp. 21-31). New York: Springer.

Stevenson, C., Kamholz, B., \& Siegler, E. L. (1994). The nursing home. In E. L. Siegler \& F. W. Whitney (Eds.), Nurse-physician collaboration: Care of adults and the elderly (pp. 5967). New York: Springer.

Stolee, P., Hillier, L. M., \& æstima research (2002). The Ontario nurse practitioner in long-term care facilities pilot project: Interim evaluation final report. Retrieved March 9, 2008, from Ministry of Health and Long-Term Care http://www.health.gov.on.ca/english/public/pub/ministry_reports/nurseprac02/np_report 022302.pdf

Stolee, P., Hillier, L. M., Esbaugh, J., Griffiths, N., \& Borrie, M. J. (2006). Examining the nurse practitioner role in long-term care: Evaluation of a pilot project in Canada. Journal of Gerontological Nursing, 32(10), 28-36.

Truscott, J. E. (2007). Nurse practitioners and GPs--addressing the needs of older persons living in residential aged care. [Review] [26 refs]. Australian Family Physician, 36(9), 765-767.

Way, D., Jones, L., \& Baskerville, N. B. (2001). Improving the effectiveness of primary health care delivery through nurse practitioner/family physician structured collaborative practice: Final report to the Health Transitions Fund. Joint University of Ottawa Department of Family Medicine and School of Nursing project funded by Health 
NP-MD Collaborative Practice 33

Canada's Health Transition Fund. Retrieved March 9, 2008, from University of Ottawa http://www.familymedicine.uottawa.ca/eng/final_report.aspx

Way, D. O., Jones, L., \& Busing, N. (2000). Implementation strategies: "Collaboration in primary care - family doctors \& nurse practitioners delivering shared care". Retrieved March 9, 2008, from Ontario College of Family Physicians www.ocfp.on.ca/include/asp/FileDownload.asp?getFile=\%7B63FE6AB0-EEB3-4EA7A67D-2DE92814AAE8\%7D

Yurkow, J. (1999). Integration and collaboration: The advanced practice nursing role in gerontologic rehabilitation. Nurse Practitioner Forum, 10(1), 20-26.

Zwarenstein, M., \& Reeves, S. (2000). What's so great about collaboration? BMJ, 320(7241), 1022-1023. 


\section{GRAPHICS}

\begin{tabular}{lccc}
\hline \multicolumn{4}{l}{ Table 1. Description of Nurse Practitioner Participants $(n=14)$} \\
\hline Characteristic & Median & Min, Max & Mean (SD) \\
\hline Age & 49 & 32,59 & $47.6(7.6)$ \\
Years practiced as RN including NP & 22.8 & $8.0,35.5$ & $22.5(9.5)$ \\
Years as RN in LTC before NP & 0 & 0,28 & $3.0(7.6)$ \\
Years practiced as NP & 3.8 & $0.5,7.5$ & $3.7(2.4)$ \\
Years worked in LTC as NP & 2.8 & $0.5,5.9$ & $3.1(2.1)$ \\
Years in the LTC home as NP & 2.8 & $0.5,5.9$ & $3.1(2.1)$ \\
\hline
\end{tabular}

$\overline{\mathrm{SD}}=$ standard deviation; $\mathrm{RN}=$ registered nurse $; \mathrm{NP}=$ nurse practitioner; $\mathrm{LTC}=$ long-term care 
Table 2. Number of Long-Term Care Homes per Nurse Practitioner, Hours Spent in Each Home, and Hours per Month Spent Collaborating with the Physician

\begin{tabular}{cccc}
\hline & & & Mean Hours per \\
Number of LTC & Number of NPs (\%) & Hours per Month in & Month \\
Homes per NP & & Each LTC Home & Collaborating with \\
& & & Identified Physician \\
\hline 1 & $4(28.6)$ & 129.0 & 18.4 \\
2 & $6(42.9)$ & 79.0 & 5.7 \\
3 & $2(14.3)$ & 52.2 & 3.0 \\
4 & $1(7.1)$ & 36.3 & 0.8 \\
10 & $1(7.1)$ & 12.2 & 0.5 \\
\hline LTC $=$ long-term care; NP = nurse practitioner & &
\end{tabular}

LTC $=$ long-term care; $\mathrm{NP}=$ nurse practitioner 
Table 3. Description of Physician Participants $(n=27)$

\begin{tabular}{|c|c|c|c|}
\hline Characteristic & Median & Min, Max & Mean $(\mathrm{SD})$ \\
\hline Age & 56 & 31,82 & $55.9(11.1)$ \\
\hline Years practiced in LTC homes & 18 & 1,40 & $17.4(11.8)$ \\
\hline Hours per month in direct & 30 & 2,120 & $29.0(23.9)$ \\
\hline resident care at the LTC home & & $\begin{array}{l}\text { (14 spend } \leq 16 \text { hours, } 1 \\
\text { outlier at } 120 \text { hours) }\end{array}$ & \\
\hline $\begin{array}{l}\text { Years worked as physician in } \\
\text { the LTC home }\end{array}$ & 10 & 1,28 & $11.8(8.4)$ \\
\hline $\begin{array}{l}\text { Years worked with the NP at } \\
\text { the LTC home }\end{array}$ & 2.0 & 0.3 (4 months), 6 years & $2.2(1.9)$ \\
\hline Hours per month collaborating & 2 & 0,48 & $7.5(10.5)$ \\
\hline with the NP & & $\begin{array}{c}\text { (16 spend } \leq 2 \text { hours, } \\
\text { Outliers: } 1 \text { at } 0 \text { hours and } \\
1 \text { at } 48 \text { hours })\end{array}$ & \\
\hline
\end{tabular}

$\mathrm{SD}=$ standard deviation $; \mathrm{LTC}=$ long-term care; $\mathrm{NP}=$ nurse practitioner 
Table 4. Overall Mean Scores for the Extent of and Satisfaction with

Collaboration for Nurse Practitioners and Physicians*

\begin{tabular}{lcccc}
\hline & N & Min** & Max** & Mean (SD) \\
MCC & & & & \\
NPs & 14 & 3.0 & 6.0 & $4.7(0.9)$ \\
Physicians*** & 27 & 1.6 & 6.0 & $4.9(1.1)$ \\
PSCC & & & & \\
NPs & 14 & 2.9 & 5.9 & $4.7(1.0)$ \\
Physicians*** & 27 & 1.9 & 6.0 & $5.3(0.9)$ \\
\hline
\end{tabular}

$\mathrm{MCC}=$ Measure of Current Collaboration; NPs $=$ nurse practitioners; $\mathrm{PSCC}=$ Provider

Satisfaction with Current Collaboration

* The mean scores are provided for information purposes, but were not used for statistical comparisons.

$* *$ Minimum mean score $=1.0$, Maximum mean score $=6.0$.

*** Includes one physician who cannot be matched with an NP. 
Table 5. Nurse Practitioner $(n=14)$ and Physician $(n=27)$ Frequency of Response to Measure of and Satisfaction with Collaboration

NPs Physicians

Characteristic (mean score interval on instrument scale) $\quad$ (number of $\quad$ (number of respondents) respondents)

MCC

Collaboration not occurring $(<3.5)$

$$
14.3 \%(2) \quad 14.8 \%(4)
$$

Collaboration occurring, but at a low level (3.5 to 4.33$)$

$14.3 \%(2)$

0

Collaboration occurring at a moderate level (4.34 to 5.17)

$$
28.6 \%(4)
$$

$40.7 \%(11)$

Collaboration occurring at a high level (5.18 to 6.0)

$42.9 \%(6)$

$44.4 \%(12)$

Total

$100 \%(14)$

$100 \%(27)$

\section{PSCC}

Dissatisfied with collaboration $(<3.5)$

$21.4 \%(3) \quad 3.7 \%(1)$

Low level of satisfaction with collaboration (3.5 to 4.33)

$7.1 \%(1) \quad 3.7 \%(1)$

Mod level of satisfaction with collaboration (4.34 to 5.17)

$42.9 \%(6)$

$37 \%(10)$

High level of satisfaction with collaboration (5.18 to 6.0)

Total
$28.6 \%(4) \quad 55.6 \%(15)$

$100 \%(14) \quad 100 \%(27)$

NPs $=$ nurse practitioners $;$ MCC $=$ Measure of Current Collaboration; PSCC $=$ Provider Satisfaction with Current Collaboration 
Table 6. Difference Between Mean Instrument Scores for Nurse Practitioners and Physicians with and without Previous Collaboration Experience

\begin{tabular}{lcccc}
\hline & Previous & $\mathrm{N}$ & Z-value* & $p$-value* \\
MCC & Experience & & & \\
NPs $(n=14)$ & & & & \\
& No & 7 & -0.38 & 0.70 \\
& Yes & 7 & & \\
Physicians $(n=27)$ & No & 14 & -0.93 & 0.35 \\
& Yes & 13 & & \\
PSCC & & & & 0.37 \\
NPs $(n=14)$ & No & 7 & -0.90 & \\
& Yes & 7 & & 0.73 \\
Physicians $(n=27)$ & No & 14 & -0.35 & \\
& Yes & 13 & & \\
& & & & \\
\hline
\end{tabular}

NPs $=$ nurse practitioners $;$ MCC $=$ Measure of Current Collaboration $;$ PSCC $=$ Provider Satisfaction with Current Collaboration

* Mann-Whitney U Test 